\title{
Address Trainee Counselors' Perplexities: Integrating Predictors of Self-Efficacy into Counseling Ethics Education
}

\author{
Neerushah Subarimaniam ${ }^{1}$, Noor Syamilah Zakaria ${ }^{1}$, \& Wan Marzuki Wan Jaafar ${ }^{1}$ \\ ${ }^{1}$ Department of Counselor Education and Counseling Psychology, Faculty of Educational Studies, Universiti \\ Putra Malaysia, Serdang, Selangor, Malaysia \\ Correspondence: Noor Syamilah Zakaria, Department of Counselor Education and Counseling Psychology, \\ Faculty of Educational Studies, Universiti Putra Malaysia, 43400 UPM Serdang, Selangor, Malaysia. Tel: \\ 603-9769-8118. E-mail: syamilah@upm.edu.my
}

Received: September 3, 2021 Accepted: September 28, 2021 Online Published: October 14, 2021

doi:10.5539/ass.v17n11p28

URL: https://doi.org/10.5539/ass.v17n11p28

\begin{abstract}
The process of addressing ethical perplexities is challenging and there is insufficiency of clear solutions and proper resources to resolve the ethical quandaries. Thus, this study aims to identify the greatest predictor of trainee counselors' self-efficacy in addressing ethical perplexities. The greatest predictor of self-efficacy is expected to enhance the existing counseling ethics education curriculum and pedagogy. A quantitative methodological approach was administered through questionnaires. There were 148 trainee counselors selected through simple random cluster sampling and they were all students from private universities in Malaysia. The data gathered were analyzed using correlation and multiple regression analyses. Correlation analysis recorded the highest coefficient of $r$ value which was a substantial relationship between self-efficacy and multicultural competence. Next, multiple regression analyses indicated that the three predictors which are multicultural competence, religiosity, and spirituality were predictive of self-efficacy. However, the strength of prediction varied. Multicultural competence had the most powerful prediction on trainee counselors' self-efficacy, followed by spirituality, and religiosity. These findings revealed the importance of the three predictors in enhancing trainee counselors' self-efficacy, addressing ethical quandaries, and developing pedagogic counseling education. The process of preparing and developing intuitive counseling professionals is worthy of attention in the counseling training and practice, specifically in addressing ethical perplexities. Thus, the three predictors should be integrated into the counselor education curriculum and pedagogy at all levels. Cultivation of these three predictors in all trainee counselors would build their level of self-efficacy and help in their survival during counseling dilemmas, leading to successful counseling sessions.
\end{abstract}

Keywords: self-efficacy, multicultural competence, religiosity, spirituality, counseling ethics education, ethical perplexities

\section{Introduction}

The process of developing intuitive counseling professionals is worthy of attention in the counseling training and practice, specifically in addressing ethical perplexities. The counseling professionals should be mindful of the codes of ethics to ensure they remain alert to the possibility of misbehaviors in counseling. For instance, trainee counselors learn to utilize ethical decision-making models when dealing with clients and at the same time, they also may be negotiating boundary-crossing issues with their counseling educators (Burns, 2019). In agreement with what Burns (2019) mentioned, trainee counselors and counselor educators should always refer to the code of ethics as it governs the principles of ethical behaviors and ethical judgements for misbehaviors which are addressed to the counseling professionals. Thus, trainee counselors need a well-designed counseling ethics education curriculum and pedagogy encompassing ethical principles and codes of ethics to ensure deliveries of effective counseling.

\subsection{Ethics in Counseling}

Ethics involves evaluation of human behaviors. It is vital to categorize those human behaviors either as 'rational' or 'irrational' (Mohd Jaladin \& Lau, 2013). The decision-making process requires ethical guidelines and moral reasoning abilities. Ethics also refers to standards and guidelines established to regulate the counseling profession. According to Mullen et al. (2014), it is an interactional process which requires counseling 
professionals' knowledge and confidence in making ethical decisions. In the Malaysian context, counseling professionals are required to adhere to the standard ethical guidelines and yardstick set by local entities such as Board of Counselors (Malaysia), International Counseling Association of Malaysia (PERKAMA International), MOE, and international bodies such as American Counseling Association (ACA), and American Psychological Association (APA). Above all, registered counselors in Malaysia are protected by Malaysian Counselor Act 1998 (Act 580) and the written law provides a guide to legal and ethical practice in counseling within the Malaysian setting. The Malaysian Counselor Act 1998 (Act 580) highlights eight different sections: (a) Preliminary; (b) The Malaysian Counselors Advisory Council; (c) The Board of Counselors; (d) Registration of Counselors and Practicing Certificates; (e) Body Corporate Practice as Counselors; (f) Disciplinary Proceedings; (g) Offences and Penalties; and (h) Miscellaneous (Counselors Act 1998 [Act 580] and Regulations, 2016; Mohd Ishak et al., 2012). The Act clearly states the responsibilities of counselors and misbehaviors that are considered offensive (Mohd Ishak et al., 2012). Furthermore, the Act assists counselors throughout the counseling process and establishes the role of counselors in the community (Mat Rani et al., 2017).

Besides the Malaysian Counselor Act 1998 (Act 580), the registered counselors in Malaysia are guided by the Counselors Code of Ethics. The Counselors Code of Ethics is used to consider ethically acceptable professional behaviors when delivering counseling services (Mohd Ishak et al., 2012). It also provides standard guidelines as the basis in overcoming ethical dilemmas in counseling and concomitantly, navigate counselors' helping profession (Mohd Ishak et al., 2012). The Counselors Code of Ethics consists of eight primary sections: (a) Counseling Relationship; (b) Confidentiality and Privacy; (c) Professional Responsibility; (d) Relationship with other Professionals; (e) Evaluation, Assessment, and Interpretation; (f) Supervision, Training, and Teaching; (g) Research and Publication; and (h) Resolving Ethical Issues (Board of Counselors [Malaysia], 2016). All the eight sections are a set of fundamental ethical guidelines that support the mission of the Board of Counselors (Malaysia) and define the functions of counselors.

\subsection{The Present Study}

This study targeted trainee counselors and limited literature reviews or research on trainee counselors' efficaciousness in addressing ethical perplexities warrants further research. According to Mullen et al. (2014), ethical and legal dilemmas are seen as a complex system and covers various branches of counseling. To date, there is insufficiency of clear solutions and proper resources to resolve the ethical quandaries (Hill, 2004; Zakaria \& Warren, 2016). Therefore, this study revealed the idea of incorporating multicultural competence, religiosity, and spirituality into the counselor education curriculum and pedagogy to develop trainee counselors' skills in addressing ethical and legal perplexities. According to Ledoux et al. (2019), influence of multicultural competence, religiosity and spirituality under professional and ethical standards may impact individuals' care choices, health, and care delivery. A similar concept is applied in the present study. Multicultural competence, religiosity, and spirituality are expected to impact trainee counselors' choices in addressing ethical and legal perplexities efficiently.

\section{Literature Review}

Multicultural competence is associated with the differences between counselor and client and those differences can be the result of traumatic life events, socialization, or ethnic environment (Gladding, 2013). In the context of current study, multicultural competency is defined as counselor's self-perceived awareness, knowledge, and skills about various cultures. According to Owen et al. (2010), one's multicultural competence leads to positive results and guides counselors in the counseling process. A counselor's responsibility of being multiculturally competent besides being empathy, non-judgmental, ethical, and so forth can be very challenging. This challenge requires counselors to be prepared and be efficacious in the aspect of multicultural counseling competency (Harun et al., 2014). Counselors who have a strong foundation in multicultural competency would be able to expand their self-efficacy in providing positive counseling outcomes (Harun et al., 2014).

On the other hand, religion refers to an individual's behaviors, thoughts, and experiences which results from a search for sacredness that gets support and validation from a society (Post \& Wade, 2014). Dalmida et al. (2012) explained further that religiosity is associated with worship that is organized by a group of people. According to Oren and Possick (2009), religiosity is beneficial during the time of stress. In the context of counseling, stress is defined as perceived pressure that is beyond one's coping ability (Gyllensten et al., 2005). Thus, perceived religiosity is crucial to help counselors cope with challenges and guide them to address legal and ethical perplexities. This would be the main focus of the current research where religiosity is measured as an influential factor that affects counselor's self-efficacy in addressing legal and ethical perplexities. Meanwhile, spirituality is a person's search for purpose and meaning of life which involves transcendence. The researchers found 
correlations between spirituality and many other aspects of lives such as job satisfaction and moral development (Curry et al., 2015). It is empirically proven that spirituality would contribute to the overall well-being of trainee counselors including being efficacious in addressing ethical and legal perplexities. On the contrary, there are even situations where human beings encounter problems due to misinterpretations of religious and spiritual elements (Ahmad et al., 2013).

The process of integrating these three domains which are multicultural competence, religiosity, and spirituality would help prepare trainee counselors to address ethical perplexities effectively by enhancing their self-efficacy beliefs. The process of incorporating multicultural competence, religiosity, and spirituality could be one of the solutions to overcome ethical perplexities in the future. The Council for Accreditation of Counseling and Related Educational Programs aspires counselors to gain experience in six areas and one of them is human growth and development. In line with the aspiration, the present study focused on multicultural competence, religiosity, and spirituality which can be classified under the area of Human Growth and Development

Multicultural competence, religiosity, and spirituality are important elements that should be instilled by every counseling professional in providing professional counseling services, specifically when addressing ethical and legal perplexities in counseling. There are counseling professionals who could not afford to digest multicultural competence, religious, and spiritual values due to their surroundings and social modeling which is accumulated with the spectrums of classism, caste system, and racism (Curry et al., 2015). Racism is defined as domination that occurs when a superior racial group is used to prescribe social status of other racial groups (Claire \& Denis, 2015) whereas caste system refers to humans' power in society and their position in the division of labor (Riswan, 2014). The spectrum of social classes is divided into three classes which are lower class, middle class, and upper class (Riswan, 2014). Finally, classism refers to a system that ranks people based on economic status, level of education, job, and family lineage (Brantley et al., 2003).

People who work for the dominant group are being controlled, work for wages, and make the dominant group's living. Thus, counseling professionals need to be aware of personal and professional challenges by mastering counseling skills, acquiring knowledge, and building capabilities to meet the expectations of the counseling profession (Chin \& Kok-Mun, 2010) specifically in the new norm. Therefore, it is important for trainee counselors to have elements of multicultural competence, religiosity, and spirituality as they are essential in building confidence that can be applied when addressing ethical challenges.

The term efficacious stemmed from the Social Cognitive Theory (SCT), a theory coined by Albert Bandura. Bandura defined self-efficacy as a person's ability to accomplish a new or challenging task and this was again highlighted by Curry et al. (2015). Bandura also revealed that people who have a high level of self-efficacy will not view ethical perplexities as problems; but see them as challenging activities that need to be overcome (Sawyer et al., 2013). This statement answers the objectives of current research. Efficacious trainee counselors would be able to overcome challenges such as ethical dilemmas and practice to overcome these issues by cultivating multicultural competence, religiosity, and spirituality. Furthermore, SCT predicts methods on how behaviors can be modified (Pei-Hsuan \& Schallert, 2008). For instance, the application of SCT would help trainee counselors who are not capable of facing ethical and legal perplexities to have some modification on their behaviors. The trainee counselors would need to modify their behaviors from being unconfident to efficacious trainee counselors and pertinent behavior modifications can be done by cultivating multicultural competence, religious, and spiritual values.

In addition, self-efficacy is defined as individuals' perception of their capability to achieve targeted goals. If trainee counselors' target is to achieve the goals of counseling sessions, then the trainee counselors are expected to be efficacious specifically when addressing ethical and legal perplexities. The efficacious beliefs hopefully can be obtained gradually upon the practice of multicultural competence, religiosity, and spirituality. For example, understanding of values, self-awareness, and self-recognition are the sub-branches of spirituality and a true human recognition leads to self-efficacy beliefs (Karami \& Imani, 2014). Thus, cultivation of spirituality helps trainee counselors to understand about self-recognition, subsequently enhancing their self-efficacy beliefs in addressing ethical and legal perplexities. Karami and Imani (2014) added that efficacious people make attempts to achieve success and do not capitulate despite the challenges and consequences encountered. This supports what SCT revealed. SCT suggested that efficacious individuals will believe in themselves, believe in their own abilities, create behaviors to achieve expected results, and make efforts or take initiatives to apply desired behaviors.

Furthermore, Warren et al. (2012) studied the use of bookmarks in teaching counseling ethics. They reported that bookmarks could be used as a toolbox to measure trainee counselors' cognitive development. The bookmark 
activity can enhance the cognitive development of trainee counselors, creates understanding of the ethical awareness, and builds competencies in ethics. Thus, this demonstrates how cognitive development, specifically in the context of social cognition, can affect trainee counselors' ethical decision-making process. Bandura even stated the influence of psychological and neurophysiological theories in the construct of 'self' where 'self' is seen as an object. However, Bandura always would not want the dualism to separate self as an agent from self as an object (Martin, 2004). According to him, every individual is an agent when he or she is executing a course of action. Thus, the current research emphasizes self-efficacy, whereby the researchers believe that efficacious trainee counselors are the agent of actions taken during the ethical and legal dilemma and they could be influenced by the three influential factors which are multicultural competence, religiosity, and spirituality.

In the light of such views, Bandura (2011) reported that Western theories cannot be generalized to non-Western cultures. For instance, social modeling is influenced by individuals' observational learning regardless of the culture that they are living in. In contrast, efficacy belief varies across cultures due to the reasons to which they have put and the way in which they are expressed. Thus, the researchers believe that the current study focusing on self-efficacy in addressing ethical and legal perplexities among trainee counselors' in Malaysia would be interesting as the country is well-known for its multiracial, multilingual, and multicultural aspects. Furthermore, the Western-based theory which is SCT disclosed that self-efficacy beliefs are the groundwork of how people feel, what people think, how they make decisions, and how people motivate themselves (Burney, 2008). This shows that the whole human makeup involves interactions of environment, behavior, and personal (see Figure 1). These interactions resemble the selection of multicultural competency, spirituality, and religiosity as influential factors in the current study.

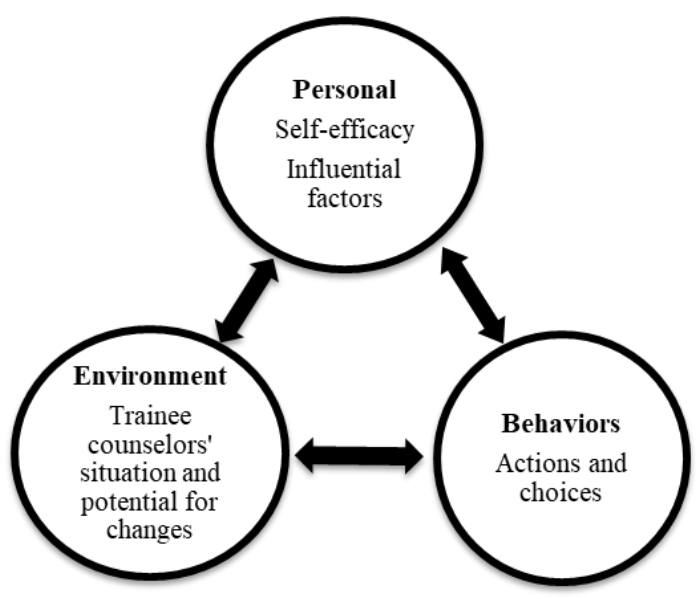

Figure 1. Interactions among personal, behavior, and environment

\section{Methodology}

\subsection{Participants}

The targeted participants are trainee counselors who are pursuing their Masters in selected private universities in Malaysia. The sample size was calculated using Cochran's (1977) formula and required 148 trainee counselors, for a population size of 243, assuming an alpha level of .05. Surveys were distributed to 148 trainee counselors consisting of four sections and 77 items. The participants were selected through simple random cluster sampling. The researchers believe that education institutions established a few years back with smaller number of trainee counselors as compared to public universities would experience challenges in having robust discussion and solutions to ethical quandaries. Furthermore, there are limited studies conducted on this research area involving trainee counselors from private universities.

\subsection{Measures}

The researchers developed a questionnaire consisting five sections and five instruments: Section A (Demographic Background); Section B (Spirituality Index of Well-Being); Section C (Religious Commitment Inventory); Section D (Multicultural Counseling Knowledge and Awareness Scale); and Section E (Ethical and Legal Issues in Counseling Self-Efficacy Scale). The details of each instrument are as follows:

\subsubsection{Spirituality Index of Well-Being (SIWB)}

The SIWB is a 5-point Likert type scale. The responses range from 1 (strongly disagree) to 5 (strongly agree). SIWB measures participants' perceptions of their quality of life in terms of spirituality. SIWB is made up of two 
subscales: (a) self-efficacy subscale; and (b) life-scheme subscale. The alpha coefficients of the subscales were .83 and .80 respectively. In addition, SIWB consists of 12 items in which item 1 to item 6 measures self-efficacy; meanwhile item 7 to item 12 is related to individuals' life-schemes. The whole SIWB scale had an alpha of .87 (Daaleman \& Frey, 2004; Daaleman et al., 2002). The internal reliability of SIWB as computed by Frey et al. (2005) was .79. Furthermore, this instrument claims good construct validity, convergent validity, and discriminant validity (Daaleman et al., 2002; Frey et al., 2005; Yi -Hui et al., 2015).

\subsubsection{Religious Commitment Inventory (RCI-10)}

The RCI-10 consists of 10 items and it is a self-report inventory that measures individuals' religious commitment. The 5-point Likert type scale which ranges from not at all true of me (1) to totally true of me (5) measures to what extend trainee counselors address their religious beliefs. Furthermore, RCI-10 is divided into two parts which are intrapersonal religious commitment consisting of six items and interpersonal commitment consisting of four items. Items 1, 3, 4, 5, 7, and 8 are under the umbrella of Intrapersonal Religious Commitment (IARC) subscale and the remaining items make up the Interpersonal Religious Commitment (IERC) subscale. Furthermore, RCI-10 has strong internal consistency, construct validity, and discriminant validity (Worthington et al., 2003). The three-week test-retest reliability values for the RCI-10 scale, IARC subscale, and IERC subscale were $.87, .86$, and .83 respectively. This instrument has strong psychometric characteristics (Miller et al., 2013).

\subsubsection{Multicultural Counseling Knowledge and Awareness Scale (MCKAS)}

The MCKAS consists of 32 items. MCKAS measures an individual's perceived multicultural competence based on two factors: (a) multicultural knowledge with 20 items; and (b) multicultural awareness with 12 items. Coefficient alpha for the multicultural knowledge scale was .92 and .78 for the multicultural awareness scale. A total of 20 items makes up the Knowledge subscale while 12 items make up the Awareness subscale. The scale is a 7-point Likert type scale and the responses range from not at all true (1) to totally true (7). A total of 10 items in MCKAS need to be reverse scored which are items 1, 4, 7, 10, 11, 18, 20, 24, 25, 26, 29, and 30 (Ponterotto et al., 1996). MCKAS recorded a good construct, criterion-related, and content validity (Chao, 2015).

\subsubsection{Ethical and Legal Issues in Counseling Self-Efficacy Scale (ELICSES).}

This instrument was developed by Mullen et al. (2014). The ethical and legal competence is one of the most difficult competencies that a researcher can define and measure (Hang Jo, 2016). The ELICSES consists of 23 items. It is a (0) Cannot Do At All to (100) Highly Certain Can Do response Likert type scale. Items 5, 6, 9, 11, $12,13,14,16,17,18,21,22$, and 23 make up the first factor, items $1,3,4,7,8,10$, and 19 make up the second factor, and finally items 2,15 , and 20 make up the third factor. The ELICSES measures trainee counselors' self-efficacy in addressing ethical and legal quandaries across three different factors:

(a) counseling self-efficacy in terms of general ethical and legal perplexities;

(b) self-efficacy for suicide, neglect, abuse, and violence; and

(c) self-efficacy for counselor development and well-being.

\section{Results}

Pearson correlation analysis as reported in Table 1 indicated a positive association between spirituality and participants' self-efficacy in addressing ethical perplexities $(r=.241, p<.05)$. Referring to Guilford's rule of thumb, correlation $r$ value between 0.20 and 0.40 would reflect a weak correlation. Therefore, the strength of the relationship between self-efficacy and spirituality is weak. Next, religiosity is positively correlated with participants' self-efficacy in addressing ethical and legal perplexities $(r=.163, p<.05)$. The relationship strength formed between self-efficacy and religiosity was almost negligible due to the small $r$ value $(<0.20)$. Next, multicultural competence is positively related to participants' self-efficacy in addressing ethical and legal perplexities $(r=.418, p<.05)$, which were also significant at $p<.01$. The $r$ value between .40 and .70 reflects a substantial relationship between self-efficacy and multicultural competence.

Table 1. Correlation coefficient of the predictors

\begin{tabular}{ccc}
\hline Predictors of Self-Efficacy & Sig. (2 tailed) & $r$ \\
\hline Spirituality & .003 & .241 \\
Religiosity & .047 & .163 \\
Multicultural competence & .000 & .418 \\
\hline
\end{tabular}


Multiple regression analysis findings as reported in Table 4 indicated that all the three factors were predictors of self-efficacy. The researchers found a significant regression equation, $[F(3,144)=17.9, p=.004]$ for the predictor of spirituality, followed by religiosity $[F(3,144)=17.9, p=.007]$ and multicultural competence $[F$ $(3,144)=17.9, p=.000$ ], with an $R^{2}$ of .272 respectively (see Table 2 and Table 3 ). $R^{2}$ was .272 which means only $27.2 \%$ of the variances predicted respondents' confidence in addressing ethical and legal perplexities. The regression analyses showed that spirituality $(\beta=.210, t=2.90, p<.05)$, religiosity $(\beta=.199, t=2.72, p<.05)$, and multicultural competence $(\beta=.452, t=6.27, p<.05)$ have significantly predicted participants' self-efficacy in addressing ethical and legal perplexities. However, the strength of prediction varied. Multicultural competence has the highest beta coefficient $(\beta=.452)$, followed by spirituality $(\beta=.452)$, and religiosity $(\beta=.199)$. Multicultural competency was the greatest predictor of trainee counselors' self-efficacy and it could be used by counseling professionals to address ethical and legal perplexities in counseling. The regression equation formed was $y=2.92 x+2.37 x^{2+} 12.8 x^{3}$.

Table 2. Model summary of multiple regression

\begin{tabular}{ccccc}
\hline Model & $R$ & $R$ Square & Adjusted $R$ Square & Std. Error of the Estimate \\
\hline 1 & $.521^{\mathrm{a}}$ & .272 & .257 & 9.84 \\
\hline
\end{tabular}

Table 3. Analysis of variance (ANOVA)

\begin{tabular}{ccccccc}
\hline & Model & Sum of Squares & $d f$ & Mean Square & $F$ & Sig. \\
\hline \multirow{3}{*}{1} & Regression & 5209.569 & 3 & 1736.523 & 17.921 & $.000^{\mathrm{a}}$ \\
& Residual & 13953.128 & 144 & 96.897 & & \\
& Total & 19162.697 & 147 & & & \\
\hline
\end{tabular}

Table 4. The coefficients of multiple regression

\begin{tabular}{cccccc}
\hline \multirow{2}{*}{ Model } & \multicolumn{2}{c}{ Unstandardized Coefficients } & Standardized Coefficients & \\
\cline { 2 - 5 } & $\mathrm{B}$ & Std. Error & Beta & \multicolumn{1}{c}{ Sig. } \\
\hline Constant & -5.52 & 10.3 & & .537 & .592 \\
Spirituality & 2.92 & 1.00 & .210 & 2.90 & .004 \\
Religiosity & 2.37 & .873 & .199 & 2.72 & .007 \\
Multicultural Competency & 12.8 & 2.04 & .452 & 6.27 & .000 \\
\hline
\end{tabular}

\section{Discussion}

There is a positive relationship between self-efficacy and spirituality. The results highlighted that trainee counselors would become more efficacious when they are more spiritual. Spirituality motivates trainee counselors in dealing with the challenges of addressing ethical and legal perplexities by improving their self-efficacy (Abou-Amerrh, 2013; Cashwell \& Watt, 2010; Hamzah et al., 2010). Spiritual participants would have strong internal strength, aware of how to react to any environment, and able to make ethical decisions. The internal strength would be an agent that trainee counselors can lean on during the period of ethical decisionmaking (Lietz \& Hodge, 2013).

Furthermore, spiritual values help in the growth of self-efficacy beliefs in every trainee counselor, who would revolutionize the beliefs into effective actions (Karami \& Imani, 2014). Thus, the relationship between self-efficacy and spirituality proves the capability of trainee counselors with spiritual values to address ethical and legal perplexities efficiently. Moreover, Oman et al. (2003) mentioned that spirituality is an agent that is associated with greater well-being, able to reframe a distressing condition, promote effective coping behaviors, increases the level of self-efficacy, and provides an inspirational passage. Thus, based on what spirituality is associated with, participants or trainee counselors will be able to address ethical and legal perplexities in counseling. This could be due to the participants' behavior modifications that result in successful reframing of challenging issues. The research conducted by Oman et al. (2003) suggested that participants who were exposed to spiritual resources such as inspirational readings and repetition of holy words reported an increase in their level of efficacious beliefs in dealing effectively with several caregiving tasks. A similar concept could be applied in the current study. Participants who have scored high in their level of spirituality would also score high in their level of self-efficacy.

The researchers also found a significant relationship between religiosity and self-efficacy. However, the 
relationship strength is weaker compared to spirituality. The results revealed that trainee counselors would become more efficacious if they are religious. Robinson and Wicks (2012) found that religious beliefs helped trainee counselors in making decisions efficiently. The value of religiosity would positively affect participants' cognition while self-efficacy would positively reframe participants' behaviors, which eventually would influence participants' ability to address ethical and legal perplexities efficiently. In this case, the participants are not required to resolve the ethical issues by themselves. Instead, they may utilize the support and advice provided by their religious groups which will boost their self-efficacy to overcome ethical issues in counseling (Stanley et al., 2011). However, the participants should make sure that their clients' confidentiality is protected.

The value of religiosity provides a platform for trainee counselors to improve their idiosyncrasies, attitudes, and behaviors (Ault, 2010; Garfield \& Isacco, 2013; McCree et al., 2003; Plante, 2008). Religiosity involves participants' participation in religious activities such as charity, prayers, religious services, and church choir. Individuals need validation from a chosen religion group to be called as a member of the group. The religious group would provide participants with more knowledge and experiences to enhance understanding of every aspect of their lives including self-efficacy. The understandings which lead to improvements in the behaviors of participants would assist in boosting their level of self-efficacy. Subsequently, the increased self-efficacy would help participants in understanding their clients better and deal with ethical issues efficiently.

Oren and Possick (2009) stated that the value of religiosity is useful when individuals are facing difficult situations which lead to stress. Stress is perceived as a condition that is beyond the individuals' coping ability (Gyllensten et al., 2005). Thus, participants who are facing ethical and legal issues would be having stress and this is when the participants would apply self-efficacy to overcome the ethical issues. Hence, it is convincing that religiosity helps in boosting participants' self-efficacy which eventually becomes one of the coping strategies used to overcome ethical issues in counseling.

The third correlation analysis recorded a positive relationship between self-efficacy and multicultural competence. This relationship is the strongest among all the relationships. The results revealed that multicultural competent trainee counselors will be able to address ethical and legal perplexities efficaciously. The greater the value of multicultural competency in trainee counselors, the better they deal with ethical issues. Multicultural competency involves trainee counselors' knowledge, awareness, and skills. Participants who could utilize their multicultural skills, knowledge, and awareness using appropriate channels or methods would be able to digest ethical and legal perplexities in counseling. This process would prove the participants' improved self-efficacy due to maximized capabilities in applying the essence of multicultural competence.

Those participants who have scored high in their level of multicultural competency would have deep affection towards their own culture and the culture of others. They understand the culture of others, have an urge to learn the culture of others, and accept other cultures equivalent to their own. The acceptance would increase the participants' level of self-efficacy as they are confident in what they are dealing with and subsequently find ways to overcome ethical perplexities in counseling.

The analysis of determining the factors that predicted participants' self-efficacy in addressing ethical and legal perplexities is the most important analysis in the current study. In essence, this analysis is the backbone as it answers the main objective of the study. The findings revealed that all the domains have significantly predicted trainee counselors' self-efficacy in addressing ethical and legal perplexities. The domains: (a) spirituality; (b) religiosity; and (c) multicultural competency have predicted trainee counselors' self-efficacy in addressing ethical and legal perplexities. These domains could serve as principles that guide people's living and be used as cognitive weapons to promote self-dignity which provide opportunities to people to perform a task more effectively. Spirituality, religiosity, and multicultural competency are the cognitive weapons that would modify the participants' behaviors, subsequently providing them with opportunities to accomplish tasks efficiently. The behavior modifications include changes from being ineffective to effective and diffidence to improved self-efficacy.

However, the power of how much each factor has predicted trainee counselors' self-efficacy varied. Multicultural competency has a large prediction on trainee counselors' self-efficacy in addressing ethical and legal perplexities. Next, spirituality has the second large prediction on trainee counselors' self-efficacy, followed by religiosity. Garfield et al. (2013) mentioned that domains such as religiosity and spirituality are effective coping behaviors that assist counselors in making decisions during the period of the ethical and legal dilemma. As Bandura (2011) and Burney (2008) stated, self-efficacy is the groundwork of all human beings' behaviors. When the domains improve trainee counselors' coping behaviors, subsequently it also enhances their self-efficacy.

The changes in coping behaviors with enhanced self-efficacy would eventually enhance the level of confidence 
in trainee counselors and prepare them in addressing ethical and legal perplexities. For instance, trainee counselors who have a low level of self-efficacy and unable to deal with ethical issues in counseling would have options to modify and improve their behaviors by cultivating multicultural competence, spirituality, and religiosity values. The cultivation would help them enhance their level of self-efficacy and eventually help them to face the ethical issues efficiently. Thus, the researchers believe that multicultural competence, spirituality, and religiosity are vital in building the level of self-efficacy in all trainee counselors.

\section{Conclusion, Limitations, and Recommendations}

Multicultural competence, spirituality, and religiosity are important domains and should be integrated into the counselor education curriculum and pedagogy at all levels. These domains can be viewed as requirements for the survival of society. Thus, cultivating these three predictors in all trainee counselors would build their level of self-efficacy and help in their survival during counseling dilemmas which would lead to successful counseling sessions. Self-efficacy should be seen as one of the important components in maintaining the quality of counseling services. The ability of trainee counselors to face ethical issues in counseling would reflect their professionalism as trained counselors. The professionalism of trainee counselors would build confidence and trust in every individual, eventually would increase the number of individuals seeking help from trainee counselors and registered counselors. The effort to develop and prepare trainee counselors should start from education institutions where trainee counselors are trained. The researchers recognized a number of limitations. The sample was recruited from three private universities. However, there was a limited number of trainee counselors studying at masters' level in Malaysian private universities. . Thus, the sample size was smaller and the results represented a smaller group of students compared to the bigger number of counseling students studying at masters' level in public universities. Next, there were limited previous studies conducted to examine trainee counselors' self-efficacy in addressing ethical perplexities. The future research may include trainee counselors from both private and public universities to generate and generalize results from a bigger population size. Upon integration of the multicultural competency, spirituality, and religiosity into the counseling ethics education pedagogy, an experimental research design can be implemented to test effectiveness of the new pedagogy.

\section{Acknowledgements}

We thank Professor Dr. Sellappan Palaniappan for his diligent proofreading of this paper.

\section{References}

Abou-Amerrh, O. A. (2013). The level of counselor self-efficacy among sample students at Hashemite University. European Journal of Business and Social Sciences, 2(3), 92-101.

Ault, M. J. (2010). Inclusion of religion and spirituality in the special education literature. The Journal of Special Education, 44(3), 176-189. https://doi.org/10.1177/0022466909336752

Bandura, A. (2011). A social cognitive perspective on positive psychology. International Journal of Social Psychology, 26(1), 7-20. https://doi.org/10.1174/021347411794078444

Brantley, C., Frost, D., Pfeffer, C., Buccigrossi, J., \& Robinson, M. (2003). Class: Power, privilege, and influence in the United States. wetWare, Inc

Brunelli, S. (2010). Human and spiritual values. The Journal of New Paradigm Research, 56(3), 219-239. https://doi.org/10.1080/02604027.2001.9972803

Burney, V. H. (2008). Applications of social cognitive theory to gifted education. Roeper Review, 30, 130-139. https://doi.org/10.1080/02783190801955335

Burns, S. T. (2019). Students' ethical decision-making when considering boundary crossings with counselor educators. Counseling and Value, 64(1), 53-71. https://doi.org/10.1002/cvj.12094

Cashwell, C. C., \& Watts, R. E. (2010). The new ASERVIC competencies for addressing spiritual and religious issues in counseling. Counseling \& Values, 55(2), 2-5. https://doi.org/10.1002/j.2161-007X.2010.tb00018.x

Chin, M. S., \& Kon-Mun, N. (2010). Counseling in Malaysia: History, current status, and future trends. Journal of Counseling and Development, 88(1), 18-22. https://doi.org/10.1002/j.1556-6678.2010.tb00144.x

Chao, R. (2015). Counselors' multicultural competencies: Race, training, ethnic identity, and color-blind racial attitudes. Vistas Online, 15, 73-76. Retrieved from https://www.counseling.org/docs/default-source/vistas/ vistas_2004_3.pdf?sfvrsn=11

Claire, M., \& Denis, J. S. (2015). Sociology of racism. International Encyclopedia of the Social and Behavioral 
Sciences, 19, 857-863. https://doi.org/10.1016/8978-0-08-097086-8.32122-5

Cochran, W. G. (1977). Sampling Techniques. John Wiley \& Sons.

Counselors Act 1998 (Act 580) and Regulations. (2005). International Law Book Services.

Curry, J. R., Arbuthnot, K. N., \& Witherspoon-Arnold, T. N. (2015). Graduate students' perceived preparation for working with client spirituality and religious values. Religion \& Education, 42(2), 184-201. https://doi.org/10.1080/15507394.2015.1021224

Daaleman, T. P., \& Frey, B. B. (2004). The spirituality index of well-being: A new instrument for health-related quality-of-life research. Annals of Family Medicine, 2(5), 499-503. https://doi.org/10.1370/afm.89

Daaleman, T. P., Frey, B. B., Wallace, D., \& Studenski, S. A. (2002). Spirituality index of well-being scale: Development and testing of a new measure. The Journal of Family Practice, 51(11), 952.

Dalmida, S. G., Holstad, M. M., Dilorio, C., \& Laderman, G. (2012). The meaning and use of spirituality among African American women living with HIV/ AIDS. Western Journal of Nursing Research, 34(6), 736-765, https://doi.org/10.1177/0193945912443740.

Frey, B. B., Daaleman, T. P., \& Peyton, V. (2005). Measuring a dimension of spirituality for health research: Validity of the spirituality index of well-being. Research on Aging, 27, 556-577.

Garfield, C. F., Isacco, A., \& Sahker, E. (2013). Religion and spirituality as important components of men's health and wellness: An analytic review. American Journal of Lifestyle Medicine, 7(1), 27-37. https://doi.org/10.1177/1559827612444530

Gladding, S. T. (2013). Counseling A Comprehensive Profession. Pearson.

Greiner, A. (2015). A quantitative examination of the use of stand-alone courses and infused curricula on middle school counselors' perceptions of preparedness with ethical and legal dilemmas (Doctoral dissertation). Retrieved from http://scholarcommons.sc.edu/etd/3185

Gyllensten, K., Palmer, S., \& Farrants, J. (2005). Perceptions of stress and stress interventions in finance organizations: Overcoming resistance towards counseling. Counseling Psychology Quarterly, 18(1), 19-29. https://doi.org/10.1080/0951507050 0099579

Hamzah, R., Md Isa, K., \& Mohd. Janor, R. (2010). Spiritual education development model. Journal of Islamic and Arabic Education, 2(2), 1-12. Retrieved from http://www.ukm.my/jiae/pdf/16.pdf/ 1985-6236

Jo, H. (2016). Development and validation of the client ratings of counselor competence: Applying the Rasch measurement model (Doctoral Dissertation). Electronic Theses and Dissertations, 5243. Retrieved from http://stars/library.ucf/etd/5243

Harun, M. M., Abdul Kadir, R., \& Mohd Noah, S. (2014). A brief review of multicultural counseling self-efficacy and multicultural counseling competency. Middle-East Journal of Scientific Research 19 (Innovation Challenges in Multidisciplinary Research \& Practice), 61-68. https://doi.org/10.5829/idosi.mejsr.2014.19.icmrp.10

Hill, A. L. (2004). Ethics education: Recommendations for an evolving discipline. Counseling \& Values, 48, 183-203. https://doi.org/10.1002/j.2161007X.2004.tb00245.x

Karami, A., \& Imani, M. N. (2014). The relation between spiritual intelligence and self-efficacy in high school teachers of District 18, Tehran, Iran. Martinia, 5(2), 100-106.

Leduox, J., Mann, C., Demoratz, M., \& Young, J. (2019). Addressing spiritual and religious influences in care

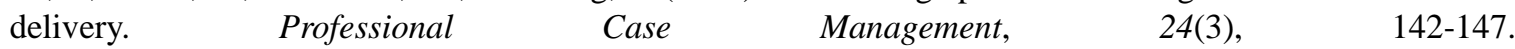
https://doi.org/10.1097/NCM.0000000000000346

Lietz, C. A., \& Hodge, D. R. (2013). Incorporating spirituality into substance abuse counseling: Examining the perspectives of service recipients and providers. Journal of Social Science Research, 39(4), 498-510. https://doi.org/10.1080/01488376.2012.676023

Martin, J. (2004). Self-regulated learning, social cognitive theory, and agency. Journal of Educational Psychologist, 39(2), 135-145. https://doi.org/10.1207/s15326985ep3902_4

Mat Rani, N. H., Wan Jaafar, W. M., Mohd Noah, S., Mohd Jais, S., \& Bistamam, M. N. (2017). An overview of counselor ethical code and ethical principles in Malaysian setting. International Journal of Academic Research in Business and Social Sciences, 7(2), 862-868. https://doi.org/10.6007/IJARBSS/v7-i2/2734 
McCree, D. H., Wingood, G. M., DiClemente, R., Davies, S., \& Harrington, K. (2003). Religiosity and risky sexual behavior in African-American adolescent females. Journal of Adolescent Health, 33(1), 2-8. https://doi.org/10.1016/S1054139x(02)00460-3

Miller, W. A., Shepperd, J. A., \& McCullough, M. E. (2013). Evaluating the religious commitment inventory for adolescents. Psychology of Religion and Spirituality, 5(4), 242-251. https://doi.org/10.1037/a0031694

Mohd Isyak, N., Amat, S., \& Abu Bakar, A. Y. (2012). Counseling professional ethics from the viewpoint of counselor educators. Journal of Educational Psychology \& Counseling, 5, 71-80.

Mohd Jaladin, R. A., \& Lau, P. L. (2013). Isu profesional dan etika dalam kaunseling dan psikoterapi. Penerbit Universiti Malaya.

Mullen, P. R., Lambie, G. W., \& Conley, A. H. (2014). Development of the ethical and legal issues in counseling self-efficacy scale. Measurement and Evaluation in Counseling and Development, 47(1), 62-78. https://doi.org/10.1177/0748175613513807

Oman, D., Hedberg, J., Downs, D., \& Parsons, D. (2003). A transcultural program to enhance caregiving self-efficacy: A pilot study. Complementary Health Practice, 8(3), 201-224. https://doi.org/10.1177/1076167502250796

Oren, L., \& Possick, C. (2009). Religiosity and posttraumatic stress following forced relocation. Journal of Loss and Trauma: International Perspectives on Stress and Coping, 14(2), 144-160. https://doi.org/10.1080/15325020902724586

Owens, D., Bodenhorn, N., \& Bryant, R. M. (2010). Self-efficacy and multicultural competence of school counselors. Journal of School Counseling, 8(17), 1-20.

Patterson, C. H. (1989). Values in counseling and psychotherapy. In Understanding Psychotherapy Fifty Years of Client-centered Theory and Practice, 33, 164-176.

Pei-Hsuan, P. H., \& Schallert, D. L. (2008). Implications from self-efficacy and attribution theories for an understanding of undergraduates' motivation in a foreign language course. Contemporary Educational Psychology, 33(4), 513-532. https://doi.org/10.1016/j.cedpsy ch.2008.01.003

Plante, T. G. (2008). What do the spiritual and religious traditions offer the practicing psychologist? Pastoral Psychology, 56(4), 429-444. https://doi.org/10.1007/s11089-008-0119-0

Ponterotto, J. G., Rieger, B. P., Barrett, A., Harris, G., \& Sparks, R. (1996). Development and initial validation of the multicultural counseling awareness scale. Multicultural Assessment in Counseling and Clinical Psychology, Paper 12, 247- 282. Retrieved from http://digitalcommons.unl.edu/burosbookmulticultural/12

Post, B. C., \& Wade, N. G. (2014). Client perspectives about religion and spirituality in group counseling. The Counseling Psychologist, 42(5), 601-627. https://doi.org/10.1177/0011000014524601.

Riswan, M. (2014). A historical survey of social class and caste system in Sri Lanka. "KALAM" International Journal of Faculty of Arts and Culture, 8(1), 40-47.

Robinson, B. K., \& Wicks, M. N. (2012). Religiosity, self-efficacy for exercise, and African American women. Journal of Religion Health, 51, 854-864. https://doi.org/10.1007/s10943-010-9397-9

Sawyer, C., Peters, M. L., \& Willis, J. (2013). Self-efficacy of beginning counselors to counsel clients in crisis. The Journal for Counselor Preparation and Supervision, 5(2), 28-43. https://doi.org/107729/52/004

Stanley, M. A., Bush, A. L., Camp, M. E., Jameson, J. P., Phillips, L. L., Barber, C. R., ... Cully, J. A. (2011). Older adults' preferences for religion/spirituality in treatment for anxiety and depression. Aging \& Mental Health, 15(3), 334-343. https://doi.org/10.1080/13607863.2010.519326

Warren, J., Covello, C., Zakaria, N. S., \& Zavaschi, G. (2012). The use of bookmarks in teaching counseling ethics. Journal of Creativity in Mental Health, 7, 2-15. https://doi.org/10.1080/15401383.2012.685027.

W. Ahmad, W. A. A., Baru, R., \& Othman, M. S. (2013). The spiritual competence aspect in counseling service. Global Journal of Human Social Science Arts \& Humanities, 13(8), 1-9. Retrived from https://globaljournals.org/GJHSS_Volume13/2-The-Spiritual-Competence-Aspect.pdf/ 2249-460X

Worthington, E. L., Wade, N. G., Hight, T. L., McCullough, M. E., Berry, J. T., Ripley, J. S., ... O'Connor, L. (2003). The religious commitment inventory-10: Development, refinement, and validation of a brief scale for research and counseling. Journal of Counseling Psychology, 50(1), 84-96. https://doi.org/10.1037/0022-0167.50.1.84 
Yi-Hui, L., Salman, A., \& Cooksey-James, T. (2015). Evaluation of the Chinese version of the Spirituality Index of Well-being (SIWB) scale in Taiwanese elders. Proceedings of the $43^{\text {rd }}$ Biennial Convention, Aria Resort and Casino, Las Vegas, Nevada, United States. Retrieved from https://stti.confex.com/stti/bc43/webprogram/Paper77041.html

Zakaria, N. S., \& Warren, J. (2016). Counseling ethics education: Teaching and learning development reformation. In I. H. Amzat, \& B. Yusuf (Eds.), Fast forwarding Higher Education Institutions for Global Challenges: Perspectives and Approaches, 83-96. Springer. https://doi.org/10.1007/978-981-287-603-4

\section{Copyrights}

Copyright for this article is retained by the author(s), with first publication rights granted to the journal.

This is an open-access article distributed under the terms and conditions of the Creative Commons Attribution license (http://creativecommons.org/licenses/by/4.0/). 